COLLOQUE DE PHYSIQUE

Colloque C2, supplément au $n^{\circ} 2$, Tome 51, Février 1990

ler Congrès Français d'Acoustique 1990

\title{
DETERMINATION OF THE TRANSDUCER VELOCITIES IN A SONAR ARRAY USING DIGITAL ACOUSTICAL HOLOGRAPHY
}

\section{AUDOLY}

Groupe d'Etudes et de Recherches de Détection Sous-Marine, D.C.A.N. Toulon, Le Brusc, F-83140 Six-Fours, France

\begin{abstract}
Résumé : Pour déterminer expérimentalement la vitesse vibratoire de transducteurs dans une antenne d'émission, on propose une méthode d'holographie numérique utilisant un modèle théorique de l'antenne basé sur l'équation intégrale de Helmholtz. La méthode a l'avantage de ne pas perturber le système (pas de montage d'accéléromètres) et nécéssite beaucoup moins de points de mesure de pression que l'holographie acoustique plane. Des simulations numériques sont effectuées sur un cas test et l'on évalue la précision de la méthode. A partir des résultats, on peut également reconstruire le champ de pression sur la surface de l'antenne et la directivité en champ lointain.
\end{abstract}

Abstract : A digital holography method, based on a Helmholtz integral equation model of a sonar array, is proposed to determine experimentally the velocities of the transducers. The method has the advantages to avoid disturbing the system (no accelerometer) and to require much less acoustic pressure measurement points than the planar holography technique. Numerical simulations are made on a test case and the accuracy of the method is evaluated. Afterwards, it is possible to obtain the surface pressure on the array and the farfield directivity pattern.

\section{INTRODUCTION}

To design sonar transducer arrays, it is useful to study acoustic interaction phenomena: frequently, the distribution of the acoustic velocity of the transducers heads is not similar to the input voltage distribution, and the array may not work in a proper way. The disadvantage of using accelerometers stuck on the heads is to disturb the system and to complicate the experimental setting. On the contrary, acoustical holography techniques can be used to obtain the acoustic velocity on the radiating surface from pressure measurements in the nearfield, without disturbing the system. A widely known method is the planar nearfield holography $/ 1,2 /$. However, the reconstruction of the velocity with enough accuracy would require a large number of measurement points. Thus, a digital holography method, based on a Helmholtz integral equation model of the array, is presented. Numerical simulations on a test case are given.

\section{DIGITAL ACOUSTICAL HOLOGRAPHY FOR SONAR ARRAYS}

In most cases, sonar arrays are composed of piezoelectric "Tonpilz" type transducers. In the low frequency range and around the first resonant frequency, the radiating heads of the transducers act like pistons. The shape of the array is modeled as a parallelepiped and the surface (except on the heads) is assumed rigid. Let $s$ be the total surface of the array, p the acoustic pressure (with implicit time dependence $\exp (i \omega t)), v_{n}$ and $S_{n}(n=1,2 \ldots N)$ the velocities and surfaces of the heads. In this case, The Helmholtz integral equation for a point $M$ of the surface is:

$$
1 / 2 p(M)-\int_{S} p(Q) \frac{\partial}{\partial n_{Q}} G(M, Q) d S(Q)=i p \omega \sum_{n=1}^{N} V_{n} \int_{S_{n}} G(M, Q) d S_{n}(Q)
$$


where $G$ is the free space Green function, $r=|m Q|$, $p$ is the volumetric mass of the surrounding fluid. This equation can be solved numerically using a piecewise constant approximation, to obtain a matrix [A] relating the surface pressure field to the unknown velocities of the pistons (see/3/for details of the procedure):

$$
[\mathrm{p}]_{\mathrm{s}}=[\mathrm{A}][\mathrm{V}]
$$

Digital holography methods were previously presented for arbitrary shaped bodies $1 / 4 /$, and in those cases the velocity distribution was unknown at all points of the body. The problem of interest here is slightly different because more information was introduced (rigid surface, piston transducers). Then [A] is not a square matrix and the size of $[p]_{s}$ (equal to the number $L$ of patches on the surface $S$ ) is much higher than the size $N$ of [V]. Typically, $N$ is less than 50 and $L$ is several hundreds.

We now select obsevation points $P_{m}, m=1, \ldots M$, in the nearfield. The acoustic pressure can be calculated using the Helmholtz integral:

$$
p\left(P_{m}\right)=\int_{S} p(Q) \frac{\partial}{\partial n_{Q}} G\left(P_{m}, Q\right) d S(Q)+i \rho \omega \sum_{n=1}^{N} V_{n} \int_{S_{n}} G\left(P_{m}, Q\right) d S_{n}(Q)
$$

Using the numerical approximation, we obtain a matrix form:

$$
[\mathrm{p}]_{\mathrm{m}}=[\mathrm{C}][\mathrm{V}]
$$

[C] is an influence matrix relating the nearfield pressure at sample points to the unknown velocities of the pistons. To provide enough information, the points should be placed in the nearfield of the pistons and $M \geq N$. The values of $p_{m}$ being determined experimentally, the piston velocities are computed by solving the system by a least-square procedure. We now present an example to show how the user can choose properly the sample points and how to ensure a realistic determination of $[\mathrm{V}]$.

\section{EXAMPLE}

The applicability of the method is tested on an array with 12 circular piston transducers. The geometry and the numerical discretisation are shown on fig.1. The size of the array is $0.6 \mathrm{~m} \times 0.45 \mathrm{~m} \times 0.3 \mathrm{~m}$. To evaluate the accuracy of the method, the following procedure is employed:

- computation of matrix [A];

- selection of observation points (receiving set) and computation of [C];

- a known set of piston velocities (reference) is introduced in the model and the theoretical "exact" pressure distribution $[p]_{m}$ is obtained;

- we introduce a random error $[\delta p]$ on $[p]_{m}$ to simulate measurement errors or a mismatch between the real array and the model;

- the reconstructed velocity of the pistons is computed by inverting [C] and compared to the reference. The accuracy is evaluated by the coefficient C. $E .=(\delta V / V) /(\delta P / P)$.

Fig.1 : Geometry of a test array of 12 transducers.

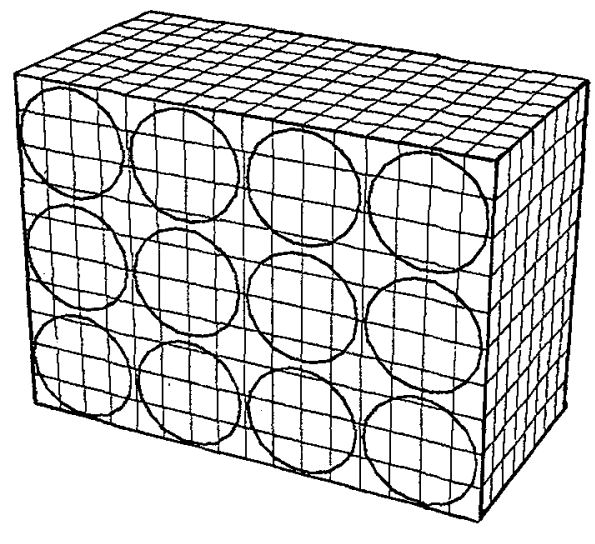


If C.E. is about 1 , the reconstruction is accurate (i.e. the error is comparable to the errors of measurement and modeling). If C.E. is over 5 , the errors are enhanced by the reconstruction, so the results are not accurate. For even larger values of $C$.E., the inversion of matrix [C] becomes impossible using the least-square technique. A single value decomposition should then be used. Physically, a large value of C.E. is related to a bad choice of the observation points (for example too far from the pistons). The computation of C.E. by simulation allows the user to choose the observation points.

For the example considered here, the number of unknowns is 12 and the pistons are set on a planar surface. We consider two receiving sets of points equally spaced on a plane of surface $s_{r}$ placed at the distance $\Delta x$ from the radiating surface:

Receiving set $\mathrm{N}^{0} 1$ : 12 points, $\mathrm{S}_{\mathrm{r}}=0.6 \mathrm{~m} \times 0.45 \mathrm{~m}$;

Receiving set $\mathrm{N}^{\circ} 2: 24$ points, $\mathrm{s}_{\mathrm{r}}=0.9 \mathrm{~m} \times 0.6 \mathrm{~m}$.

The evolution of C.E. with respect to distance $\Delta x$, and for different frequencies, are given on fig.2 and fig.3. Above $5000 \mathrm{~Hz}$, corresponding to a half-wavelength spacing of the centers of the transducers, the reconstruction is good, even for large $\Delta x$. At lower frequencies, the error increases with $\Delta x$. Receiving set $N^{\circ} 2$ gives better results. Table I gives an example with $f=2500$ $\mathrm{Hz}, \Delta \mathrm{x}=4 \mathrm{~cm}$ and $\delta \mathrm{p} / \mathrm{p}=0.1$. The error coefficient is 1.68 . Once the velocities are known, the farfield directivity patterns can be computed. Fig. 4 compares the reconstruction and the reference. The results are in good agreement. Note that the determination of the piston velocities has required only 24 measurement points instead of $32 \times 32$ points for a classical planar holography technique.

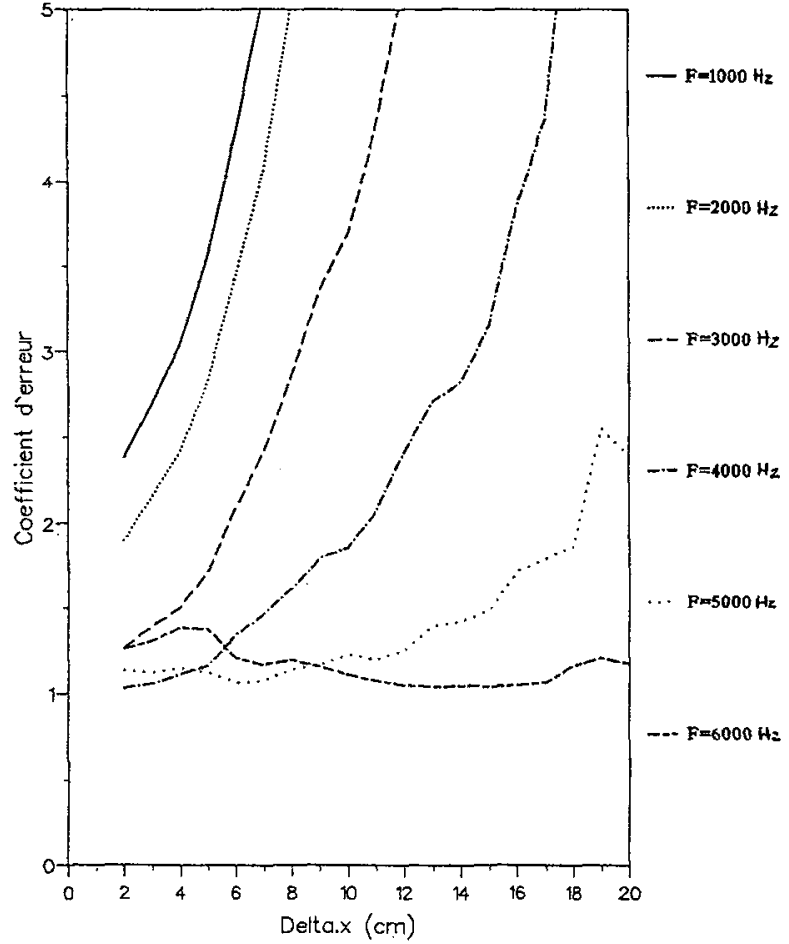

Fig.2 : Error coefficient vs distance $\delta \mathrm{x}$ for receiving set $\mathrm{N}^{\circ} 1$.

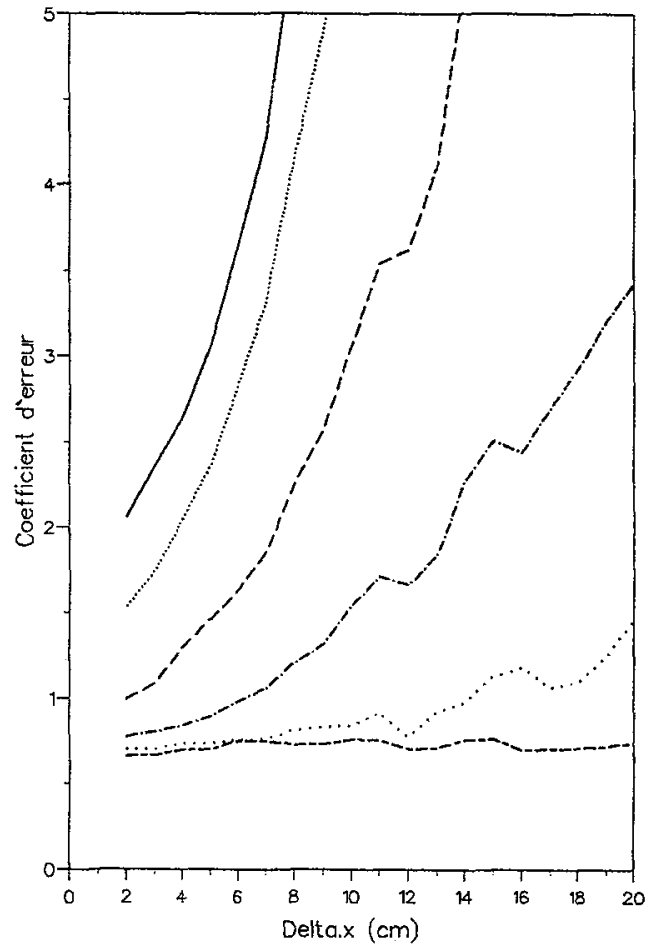

Fig.3 : Error coefficient vs distance $\delta \mathrm{x}$ for receiving set $\mathrm{N}^{0} 2$. 


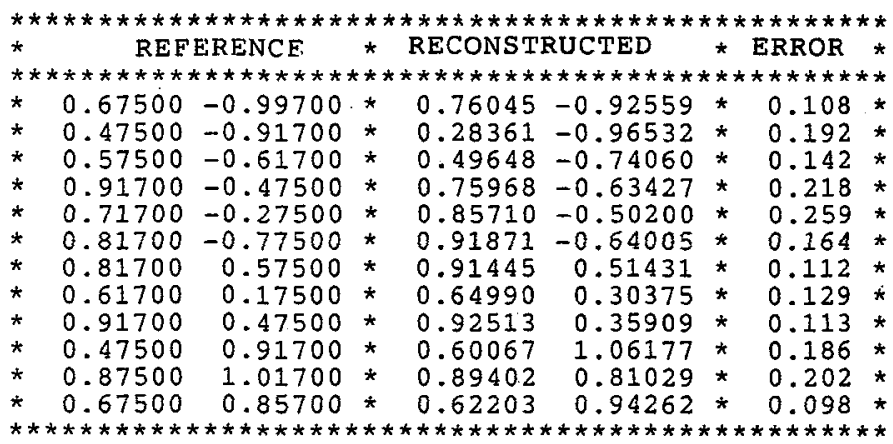

Table I : Comparison of reconstructed and reference piston velocities for receiving set $\mathrm{N}^{\circ} 2$ at $f=2500 \mathrm{~Hz}$ with $\delta \mathrm{p} / \mathrm{p}=0.1$. Real and Imaginary parts.

80

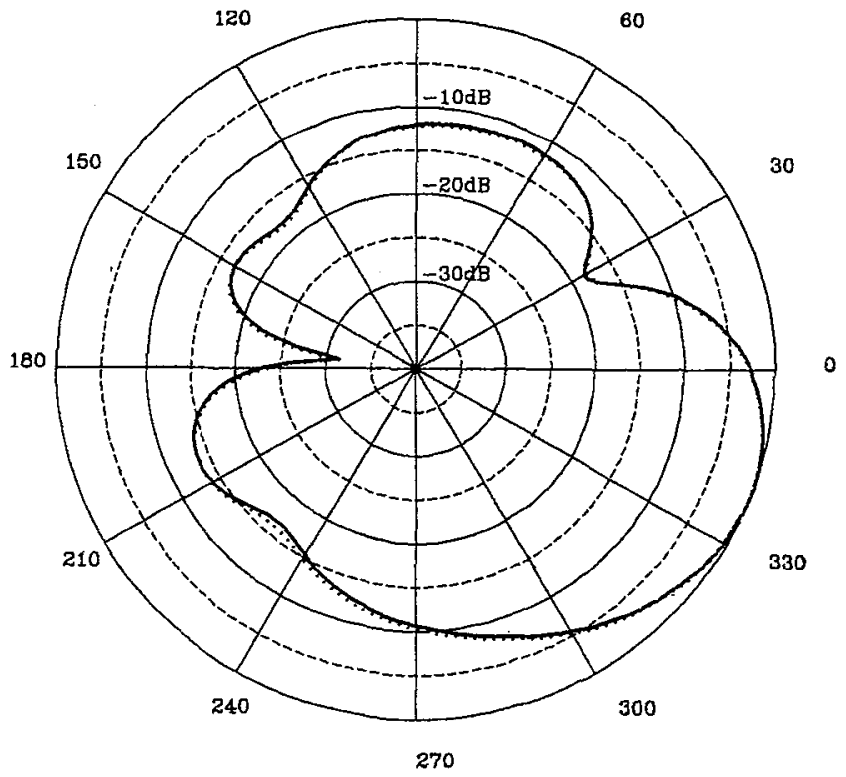

Fig. 4 : Comparison of reconstructed and reference farfield directivity pattern at $\mathbf{f}=2500 \mathrm{~Hz}$ : $(-)$ reference; $(\ldots . .$.$) reconstructed.$

\section{REFERENCES}

11/ MAYNARD J.D., WILLIAMS E.G. and LEE Y., J.ACOust.SOC.AM. $79(1985) 1395$.

12 VERONESI $\mathrm{W} . \mathrm{A}$. and MAYNARD J.D., J.Acoust.SOC.Am. 81(1987) 1307.

13/ AUDOLY.C, Acoustic interaction effects in unbaffled transducer arrays, J.Acoust. Soc.Am. 83 Suppl.1 (spring 1988).

14/ VERONESI W.A. and MAYNARD J.D., J.Acoust.SOC.Am. 85(1989)588. 